William T. Abraham, MD

Ohio State University

Columbus

Barry H. Greenberg, MD

University of California San Diego Medical Center-Hillcrest San Diego

Financial Disclosures: Dr Fonarow reports that he has received research grant from Amgen, Biosite, Bristol-Myers Squibb, Boston Scientific/Guidant, GlaxoSmithKline, Medtronic, Merck, Pfizer, Sanofi-Aventis, and Scios; that he is/has been on the speaker's bureau or has received honoraria in the past 5 years from Amgen, AstraZeneca, Biosite, Bristol-Myers Squibb, Boston Scientific/Guidant, GlaxoSmithKline, Kos, Medtronic, Merck, NitroMed, Pfizer, Sanofi-Aventis, Schering-Plough, Scios, St Jude Medical, Takeda, and Wyeth and that he is or has been a consultant for Biosite, Bristol-Myers Squibb, Boston Scientific/Guidant, GlaxoSmithKline, Medtronic, Merck, Medical, NitroMed Orqis Medical, Pfizer, Sanofi, Schering-Plough, Scios, and Wyeth. Dr Yancy reports that he has received research grants from Cardiodynamics, GlaxoSmithKline, Scios, Medtronic, and NitroMed; that he is a consultant or on the speaker"'s bureau for AstraZeneca, Cardiodynamics, GlaxoSmithKline, Medtronic, NitroMed, Novartis, and Scios; that he is on the advisory board fo CHF Solutions, a US Food and Drug Administration cardiovascular device panel, and the National Institutes of Health; that he has received honoraria from Ast raZeneca, Cardiodynamics, GlaxoSmithKline, Medtronic, Novartis, and Scios; and that he has editorial board involvement with Circulation (guest editor), Congestive Heart Failure, Current Heart Failure Reports, Journal of Acute Cardiac Care, Journal of Urban Cardiology, and the American Heart Journal. D Abraham reports that he has received research grants from Amgen, Biotronik, CHF Solutions, GlaxoSmithKline, the Heart Failure Society of America Medtronic, Myogen, the National Institutes of Health, Orqis Medical, Otsuka Maryland Research Institute, Paracor, and Scios; that he is or has been a consultant or served on the speaker's bureau for Amgen, AstraZeneca, BoehringerIngelheim, CHF Solutions, GlaxoSmithKline, Guidant, Medtronic, Merck, Pfizer ResMed, Respironics, Scios, and St Jude Medical; that he is on the advisory board of CardioKine, CardioKinetix Inc, CHF Solutions, the Department of Veterans Affairs Cooperative Studies Program, Inovise, the National Institutes of Health, and Savacor; that he has received honoraria from AstraZeneca, Boehringer-Ingelheim, GlaxoSmithKline, Guidant, Medtronic, Merck, Pfizer ResMed, Respironics, Scios, and St Jude Medical, and that he has editoria board involvement with Congestive Heart Failure, Current Cardiology Reviews, Current Heart Failure Reports, Expert Review of Cardiovascular Therapy, Journal Watch Cardiology, PACE-Pacing and Clinical Electrophysiology, the American Heart Hospital Journal, and the Journal of Heart Failure. Dr Greenberg reports that he has received research grant support from Amgen, Cardiodynamics, GlaxoSmithKline, Millennium, Novacardia, Otsuka, Pfizer, SanofiAventis, and Titan; that he is on the speaker's bureau and/or serves as consultant for Amgen, AstraZeneca, GlaxoSmithKline, Guidant, Medtronic, Merck, Pfizer, Remon Medical Technologies, and Scios; that he is an advisory board member for CHF Solutions; that he has received honoraria from AstraZeneca, GlaxoSmithKline, Medtronic, Merck, NitroMed, Novartis, Pfizer, and Scios; and that he has had editorial board involvement with Congestive Heart Failure and Journal of the American College of Cardiology.

1. Califf RM, Peterson ED, Gibbons RJ, et al. Integrating quality into the cycle of therapeutic development. J Am Coll Cardiol. 2002;40:1895-1901.

2. Bonow RO, Bennett S, Casey DE Jr, et al; American College of Cardiology; American Heart Association Task Force on Performance Measures (Writing Committee to Develop Heart Failure Clinical Performance Measures); Heart Failure Society of America. ACC/AHA clinical performance measures for adults with chronic hear failure: a report of the American College of Cardiology/American Heart Association Task Force on Performance Measures. J Am Coll Cardiol. 2005;46:11441178.

3. Hunt SA; American College of Cardiology; American Heart Association Task Force on Practice Guidelines (Writing Committee to Update the 2001 Guidelines for the Evaluation and Management of Heart Failure). ACC/AHA 2005 guideline update for the diagnosis and management of chronic heart failure in the adult: a report of the American College of Cardiology/American Heart Association Task Force on Practice Guidelines (Committee to Update the 2001 Guidelines for the Evaluation and Management of Heart Failure). J Am Coll Cardiol. 2005;46:e1-e82 4. Heart Failure Society of America. HFSA 2006 comprehensive heart failure prac tice guideline: section 7: heart failure in patients with left ventricular systolic dysfunction. J Card Fail. 2006:12:e38-e57.

5. Gattis WA, O'Connor CM, Gallup DS, Hasselblad V, Gheorghiade M. Predischarge initiation of carvedilol in patients hospitalized for decompensated heart failure: results of the Initiation Management Predischarge: Process for Assessment of Carvedilol Therapy in Heart Failure (IMPACT-HF) trial. J Am Coll Cardiol. 2004;43: 1534-1541.

\section{Folic Acid Supplementation and Cardiovascular Diseases}

To the Editor: In their meta-analysis of randomized controlled trials of folic acid supplementation and risk of cardiovascular disease, Dr Bazzano and colleagues ${ }^{1}$ provided a clear description of their inclusion criteria and study selection process. Using multiple databases when searching for studies that meet meta-analysis inclusion criteria may help avoid selection bias. ${ }^{2}$ Failure to search multiple health databases can result in missing up to half of the relevant literature. ${ }^{3}$

EMBASE and MEDLINE are the 2 most comprehensive databases used in meta-analyses. EMBASE focuses on drugs and pharmacology and contains more than 18 million records, including an index of more than 7000 journals from 70 countries. It may be a relevant source of negative studies, because European and non-English-language journals may be more likely to publish negative findings. However, Bazzano et al limited their literature search to MEDLINE. In addition, an important source for obtaining negative studies is hand searching of "grey literature" (such as abstracts from major meetings and symposiums, newsletters, and theses). Omitting gray literature from meta-analyses can affect analysis outcome by as much as $15 \%{ }^{4}$

Suhal S. Mahid, MRCS, PhD

ssmahi01@louisville.edu

Kyle S. Minor, BA

Susan Galandiuk, MD

Price Institute of Surgical Research

University of Louisville

Louisville, Ky

Financial Disclosures: None reported

1. Bazzano LA, Reynolds K, Holder KN, He J. Effect of folic acid supplementation on risk of cardiovascular diseases: a meta-analysis of randomized controlled trials. JAMA. 2006;296:2720-2726

2. Sampson M, Barrowman NJ, Moher D, et al. Should meta-analysts search EMBASE in addition to MEDLINE? J Clin Epidemiol. 2003;56:943-955.

3. Dickersin K, Scherer R, Lefebvre C. Identifying relevant studies for systematic reviews. BMJ. 1994;309:1286-1291.

4. McAuley L, Pham B, Tugwell P, Moher D. Does the inclusion of grey literature influence estimates of intervention effectiveness reported in meta-analyses? Lancet. 2000;356:1228-1231.

To the Editor: Several large prospective observational studies and a recent meta-analysis ${ }^{1}$ suggested an association between elevated levels of homocysteine and risk of cardiovascular diseases. A population-based cohort study found that folate supplementation is effective in decreasing total homocysteine concentration. ${ }^{2}$ However, the meta-analysis of randomized controlled trials by Dr Bazzano and colleagues ${ }^{3}$ did not find any effect of folic acid supplementation on the risk of cardiovascular diseases or all-cause mortality among patients with a prior history of vascular disease.

The authors suggested possible factors that may have contributed to the discrepancy between the results of their metaanalysis and those of observational studies, including the presence of confounding factors in observational studies, the lack of efficacy of folic acid supplementation in secondary preven- 
tion, and the beneficial effect of folic acid supplementation only in populations with specific genetic backgrounds or with folate deficiency. However, the inefficacy of folate supplementation in reducing the risk of cardiovascular diseases may be dependent on other mechanisms that should be explored.

First, since implementation of a 1996 US Food and Drug Administration regulation, flour, rice, pasta, and other grain products have been fortified with folic acid. ${ }^{4}$ Because all 12 studies included in this meta-analysis enrolled patients after 1996, the number of patients with increased homocysteine levels at the time of the enrollment may be small. Fortification of grain in the country of origin of the studies was used in only 4 of the 12 studies. However, these studies included more than 10000 of the 16000 patients, and mean homocysteine levels were higher than $15 \mu \mathrm{mol} / \mathrm{L}$ in only 4 studies. Furthermore, the difference in homocysteine concentration achieved between the vitamin supplementation group and the placebo or usual-care groups may be very small. Appropriate sensitivity analyses should explore the validity of these hypotheses.

Second, recent data suggest that homocysteine levels are related to other established cardiovascular risk factors such as smoking, elevated blood pressure, and presence of the metabolic syndrome. ${ }^{5}$ Therefore, hyperhomocysteinemia could be a marker and not an independent risk factor for cardiovascular disease.

Francesco Dentali, MD

fdentali@libero.it

Monica Gianni, MD

Walter Ageno, MD

Department of Clinical Medicine

Insubria University

Varese, Italy

Financial Disclosures: None reported

1. Homocysteine Studies Collaboration. Homocysteine and risk of ischemic heart disease and stroke: a meta-analysis. JAMA. 2002;288:2015-2022.

2. Jacques PF, Selhub J, Bostom AG, Wilson PW, Rosenberg IH. The effect of folic acid fortification on plasma folate and total homocysteine concentrations. N Engl J Med. 1999:340:1449-1454.

3. Bazzano LA, Reynolds K, Holder KN, He J. Effect of folic acid supplementation on risk of cardiovascular diseases: a meta-analysis of randomized controlled trials. JAMA. 2006;296:2720-2726.

4. US Food and Drug Administration. Food standards: amendment of standards of identity for enriched grain products to require addition of folic acid. Fed Regist. 1996;61:8781-8797.

5. Hajer GR, van der Graaf Y, Olijhoek JK, Verhaar MC, Visseren FL. Levels of homocysteine are increased in metabolic syndrome patients but are not associated with an increased cardiovascular risk, in contrast to patients without the metabolic syndrome [published online ahead of print September 4, 2006]. Heart. doi: 10.1136/hrt.2006.093971. Accessed February 26, 2007.

In Reply: In response to Dr Mahid and colleagues, although we did not have access to EMBASE, we did conduct bibliographic searches of review articles and included abstracts from the "grey literature" through these searches. For example, the results of Baker et al were published only in abstract form. ${ }^{1}$ We agree that searching this type of literature is particularly important for finding negative studies, because positive findings are more likely to be published in peer-reviewed journals indexed by MEDLINE. In the case of our pooled analy- sis, we identified no association between folic acid supplementation and the risk of cardiovascular diseases or allcause mortality.

We have searched the EMBASE database using identical terms and limits and identified 240 references that were screened; only 1 additional study met our inclusion criteria. ${ }^{2}$ This study found no difference between the folic acid supplementation group and control group in rate of instent restenosis after percutaneous coronary intervention. ${ }^{2}$ Addition of this negative study to our pooled estimate would not have affected our results.

Dr Dentali and colleagues suggest that fortification of grains with folic acid could have been responsible for the lack of association in our study. Of the included trials, 4 (10 027 participants) were conducted in countries with folic acid fortification of grains, while 8 (6931 participants) were conducted in countries without folic acid fortification of grains. We conducted a sensitivity analysis to determine if fortification in the country of study origin affected our results. The confidence intervals of all pooled estimates crossed 1 , so none of the results changed.

Dentali et al also suggest that lower baseline homocysteine levels may have affected our results. However, in sensitivity analyses, no significant effect of folic acid supplementation was found in pooled estimates among the 5 studies (4876 participants) with baseline homocysteine levels greater than the median value of $13.1 \mu \mathrm{mol} / \mathrm{L}$. We agree that the possibility exists for hyperhomocysteinemia to be a marker, rather than an independent risk factor, for cardiovascular disease.

We want to highlight the importance of the planned pooled analysis by the B-Vitamin Treatment Trialists' Collaboration. ${ }^{3}$ Their analysis will include approximately 52000 participants and will have sufficient power to determine whether lowering homocysteine levels by approximately $25 \%$ reduces the risk of coronary heart disease by $10 \%$ or more.

Lydia A. Bazzano, MD, PhD

lbazzano@tulane.edu

Kristi Reynolds, PhD

Department of Epidemiology

Tulane University School of Public Health and Tropical Medicine

Kevin N. Holder, MD

Department of Medicine

Tulane University School of Medicine

Jiang He, MD, PhD

Department of Epidemiology

Tulane University School of Public Health and Tropical Medicine

New Orleans, La

Financial Disclosures: None reported.

1. Baker F, Picton D, Blackwood S, et al. Blinded comparison of folic acid and placebo in patients with ischemic heart disease: an outcome trial. Circulation. 2002; 106(suppl 2):741S

2. Namazi $M H$, Motamedi $M R$, Safi $M$, Vakili $H$, Saadat $H$, Nazari N. Efficacy of folic acid therapy for prevention of in-stent restenosis: a randomized clinical trial. Arch Iran Med. 2006;9:108-110.

3. B-Vitamin Treatment Trialists' Collaboration. Homocysteine-lowering trials for prevention of cardiovascular events: a review of the design and power of the large randomized trials. Am Heart J. 2006;151:282-287. 